\title{
Arte y ostentación en el Renacimiento: Los tapices flamencos del Inquisidor y Arzobispo de Zaragoza Andrés Santos (1529-1585)
}

\author{
Mar AZnAR RECUENCO \\ Departamento de Historia del Arte \\ Universidad de Zaragoza \\ maraznar@unizar.es
}

\section{RESUMEN}

Estudio de los tapices flamencos propiedad de Andrés Santos, arzobispo de Zaragoza (1579-1585). En él se realiza una primera aproximación a su biografía y se presentan nuevos hallazgos documentales sobre algunas de estas piezas, como en el caso de las dos series de tapices y los dos tapices heráldicos del Duque de Calabria custodiados en el Museo de Tapices de la Seo de Zaragoza.

Palabras clave: tapices; Renacimiento; Zaragoza; Santos; arzobispo.

\section{Art and ostentation in the Renaissance: Flemish tapestries of the Inquisitor an Archbishop of Zaragoza Andrés Santos (1529-1585)}

\begin{abstract}
Study of the collection of Flemish tapestries owned by Andrés Santos, archbishop of Zaragoza (15791585). The paper makes a first approach to his biography and introduces the new findings of historical documentation for some of these artworks, such as the two tapestries' series and two heraldic tapestries of the Duke of Calabria that are kept in the Seo's Tapestry Museum of Zaragoza.
\end{abstract}

Key words: tapestries; Renaissance; Zaragoza; Santos; archbishop. 
"La realidad supera a lo creíble: los telares comenzaron a reverdecer y los tapices que colgaban a echar hojas a modo de hiedra; unos se convierten en vides y lo que hace poco eran hilos se transforman en sarmientos (...)"

Ovidio, Metamorfosis, Libro IV, 390-400.

En las colecciones españolas, tanto eclesiales como civiles, se custodian numerosos tapices fechados en el siglo XVI y tejidos en talleres de Bruselas, que debemos a la adquisición de patrocinadores del Renacimiento español, tanto pertenecientes a la Casa Real, como a casas nobiliarias o a personajes que ostentaron importantes dignidades de índole eclesiástica. La figura del inquisidor, obispo de Teruel y arzobispo de Zaragoza Andrés Santos guarda interés en el estudio de los veintidós tapices que poseyó, piezas conservadas en el Museo de Tapices de la Seo de Zaragoza.

Para adentrarnos en el ámbito del estudio de estos tapices, debemos dar a conocer brevemente la personalidad y trayectoria político-eclesiástica del prelado ${ }^{1}$. Andrés Santos nació el año 1529 en la localidad de Quintanadíez de la Vega (Palencia) y las últimas investigaciones revelan que pertenecía a una humilde familia de "hijosdalgo". Sus verdaderos apellidos eran Izquierdo Quexada, por lo que debió tomar el apellido de su abuela paterna, Catalina Santos, con la que se pudo criar. Sabemos que en el año 1559 estudiaba en el Colegio-Universidad de San Antonio de Portacelli de Sigüenza, aunque desconocemos cómo pudo costearse unos estudios universitarios, y menos aún cómo el mismo año pasó a ejercer como procurador en Carrión de los Condes (Palencia). Transitó por diversos tribunales de la Inquisición peninsulares ejerciendo como fiscal en Valladolid, donde de momento nos aparece documentado desde 1560 a 1564, Llerena, Cuenca, Córdoba, Valencia (1568), de nuevo Valladolid y Zaragoza (1575), respectivamente. Durante su trayectoria profesional como funcionario del Santo Oficio en España, se ganó la confianza del monarca Felipe II, motivo por el que llegó a ostentar la dignidad eclesiástica de obispo de Teruel, sede recién creada de la que tomó posesión en 1578. Posteriormente fue elegido arzobispo de Zaragoza con la consecuente toma de la sede de la archidiócesis el cuatro de julio de 1579, y perteneció al Consejo de "Su Majestad". La relación del prelado con la Compañía de Jesús, queda patente en el escudo de armas del propio arzobispo zaragozano en el que campea el monograma de los jesuitas. Una vinculación que lo llevó a acordar el 4 de diciembre de 1579 la apertura de la Escuela de Gramática que pasó a ser de la competencia de la Compañía, y a donarles rentas y bienes en sus legados testamentarios. Otro de sus méritos fue el de convocar un Sínodo Provincial que tuvo

\footnotetext{
1 Todos los datos que aportamos a continuación son el fruto de la recopilación del estado de la cuestión y las nuevas noticias documentales vertidas enel artículo de investigación publicado en: AZNAR RECUENCO, Mar, "El valor del prestigio: introducción a la biografía y empresas artísticas financiadas por el inquisidor y arzobispo de Zaragoza Andrés Santos", en Aragonia Sacra, n² 21, 2011, pp. 7-35.
} 
como fin la instauración total de los cánones vertidos por el Concilio tridentino, y realizar una visita pastoral entre 1581 y 1582 a la totalidad de los municipios de la archidiócesis zaragozana. Asimismo, Andrés Santos publicó un libro en el que se dan instrucciones sobre el Sacramento de la Penitencia.

Además de las actividades de índole eclesiástica, el arzobispo Andrés Santos sirvió como informador en relación a los conflictos de Felipe II con sus súbditos de la Ribagorza (Huesca) y atendió personalmente al monarca y a sus familiares en su visita a Zaragoza con motivo del enlace de la infanta Catalina Micaela con el Duque de Saboya en 1585. Su muerte acaeció durante la celebración de las Cortes de Monzón (Huesca) el día 13 de noviembre de 1585, y fue inhumado en la capilla de la Virgen Blanca de la Seo de Zaragoza, tal y como pactó con el cabildo antes de su marcha a Monzón con motivo de la celebración de las Cortes. En el año 1646, los restos mortales de Andrés Santos fueron exhumados de la capilla de la Virgen Blanca de la Seo de Zaragoza para ser llevados a la iglesia parroquial de Quintanadíez de la Vega (Palencia), localidad natal del prelado y la mayor beneficiaria de sus legados testamentarios.

\section{LOS TAPICES DE ANDRÉS SANTOS EN LA SEO DE ZARAGOZA}

Como todo hombre de prestigio, Andrés Santos contó con la posesión de dos series de tapices y dos paños heráldicos que se conservan en el Museo de Tapices de la Seo de Zaragoza ${ }^{2}$. Nuestra investigación en el Archivo Capitular de la Seo de Zaragoza, el Archivo Histórico de Protocolos Notariales de Zaragoza y el Archivo Histórico Nacional de Madrid, ha dado como fruto la exhumación de varias noticias nuevas sobre la llegada de dichos paños a la colección del cabildo de Zaragoza, así como la documentación que certifica la compra de Andrés Santos durante su estancia como inquisidor en Valencia de los dos tapices heráldicos con el escudo de armas del Duque de Calabria. Las piezas de tapicería que pertenecieron a Andrés Santos llegaron a los fondos de la sede primada por dos vías: a través de la donación del propio arzobispo y mediante la compra hecha en la almoneda de los bienes del difunto prelado por parte del cabildo ${ }^{3}$.

\footnotetext{
2 Se han realizado varios estudios sobre estas piezas de tapicería en publicaciones relacionadas con las colecciones de tapices existentes en Aragón y sobre los paños pertenecientes a la Seo de Zaragoza, vid: RÁBANOS FACI, Carmen, Los Tapices en Aragón, Zaragoza, Librería General, 1978, p. 19, pp. 60-65 y pp. 73-76; TORRA DE ARANA, Eduardo, HOMBRÍA TORTAJADA, Antero, y DOMINGO PÉREZ, Tomás, Los Tapices de la Seo de Zaragoza, Zaragoza, Caja de Ahorros de la Inmaculada, 1985, pp. 51-52, 263-291, 239270 y 318-320; BOSQUED LACAMBRA, Pilar, Flora y vegetación en los tapices de La Seo, Zaragoza, Caja de Ahorros de la Inmaculada en Aragón, 1989. La publicación más completa hasta el momento sobre tapices, vid: CAMPBELL, Thomas P., Tapestry in the Renaissance. Art and Magnificence, catalogue exhibition (New York, March 12-June 19), New York, Metropolitan Museum of Art, Yale University Press, 2002.

3 Archivo Capitular de la Seo de Zaragoza (citaré: ACSZ), Inventario de Sacristía, 1594, f. 69. Las tapicerías se adquirieron en enero de 1586, con Miguel de Azcona y Balthasar de Aquiñigo, Martín de Sierra y el canónigo de catedral metropolitana Pedro Torrellas como corredores de la almoneda del arzobispo Andrés Santos en nombre del cabildo. Se compraron "tapiçerias, alombras, damascos y otras cosas"; ACSZ, Recibos de Sacristía, Caja núm. 33, $19-01-586$.
} 


\section{TAPICES DONADOS POR ANDRÉS SANTOS A LA METROPOLITANA DE ZA- RAGOZA: LA SERIE DE LOS MESES O DEL ZODÍACO}

Andrés Santos donó a la sede metropolitana de San Salvador de Zaragoza una serie de tapices dedicada a los Meses, también llamada del Zodíaco, siguiendo la estela de las donaciones hechas a la colección catedralicia por los arzobispos de la Casa Real de Aragón, como en el caso de don Alonso, don Juan y don Hernando de Aragón. El documento de donación se fecha el 15 de junio de 1585, tan sólo dos días después de la celebración de la boda de la hija del monarca Felipe II, Catalina Micaela, con el Duque de Saboya, y en él se establece que la serie se dona "desseando aumentar cosas del adorno de nuestra metropolitana yglesia de la ciudad de Çaragoça" para gozar de unas tapicerías dignas con que engalanar la catedral durante las festividades del Corpus y en su Octavario ${ }^{4}$. Otra de las posibilidades anotadas en el documento es la de ser prestados a las "personas reales" y a los arzobispos que tuviesen necesidad de engalanar sus estancias personales en el palacio arzobispal ${ }^{5}$.

La serie de los Meses cuenta con doce paños confeccionados en talleres de Bruselas siguiendo la técnica del bajo lizo, predominante en la segunda mitad del siglo XVI, y está centrada en la representación de los cambios estacionales y su correspondencia con los signos zodiacales. El tema de los meses del año equiparados a los signos del zodíaco y las edades del hombre, nace del pensamiento geocéntrico de la astrología medieval que siguió presente en la tradición y cultura del Renacimiento. Tal y como señala Paracelso, en el hombre como hijo de Dios "está el "joven cielo", es decir, todos los planetas están hechos a imagen del hombre y son hijos del Gran Cielo, que es su padre. ¡Pero el hombre ha sido creado de cielo y tierra, y es por tanto igual a ellos!" 6 . Por tanto, el hombre, los astros y la tierra permanecen indefectiblemente vinculados e influenciados unos por otros. Los tapices representan en su campo central temas religiosos, profanos e historias mitológicas narradas en las cartelas situadas en el primer plano con una didascalia latina destinada a identificar la escena principal ${ }^{7}$, y combinados con una representación agrícola propia de cada uno de los

4 Archivo Histórico de Protocolos Notariales de Zaragoza (citaré: AHPNZ), Sebastián Moles, 1585, ff. 446v-447v; TORRA DE ARANA, Eduardo, HOMBRÍA TORTAJADA, Antero, y DOMINGO PÉREZ, Tomás (1985), op. cit., p. 51. Esta serie aparece citada en el Inventario de Sacristía de 1594 en el Archivo Capitular de la Seo, vid: ACSZ, Inventario de Sacristía, 1594, f. 69. Sabemos que en agosto de 1585 los paños aún no habían llegado a manos de los representates del cabildo: ACSZ, Recibos de Sacristía, 17-08- 1585. Recibo firmado por el notario de la corte en Zaragoza Juan Iturralde, en el que se testifica el pago hecho por el cabildo zaragozano de sesenta sueldos jaqueses por la insinuación de la donación de los doce paños de tapicería del Ilmo sr. arzobispo. El mismo 17 de agosto los paños se entregaron a la Corporación.

5 "Hago donación de doce paños que llaman de los meses de seis annas de cayda, que por todas son 600 annas, a nuestra yglesia metropolitana de Zaragoza para el adorno de ella en las fiestas del Corpus y de su Octavario, y las obras que se celebrase en dicha iglesia que pareciere; con que no los puedan prestar sino a los prelados que por tiempo seran desta iglesia y para cualquiera otra casa de esta ciudad en caso que haya que posar en ella alguna de las personas Reales. [Testes: Micer Joan Ribas]", AHPNZ, Sebastián Moles, 1585, s.f. (entre ff. 445 v y $446 r$.).

6 PARACELSO, Textos esenciales, Madrid, Siruela, 1991, pp.74-75.

7 En relación a las escenas de religiosas: Virgo muestra a José previniendo el hambre en Egipto, en Sagitario se representan los consejos del anciano Tobías a su hijo, en Capricornio, Jacob moribundo bendice a los hijos de José, en Acuario Moisés niño rompe la corona al faraón. Las historias mitológicas se encuentran en las 


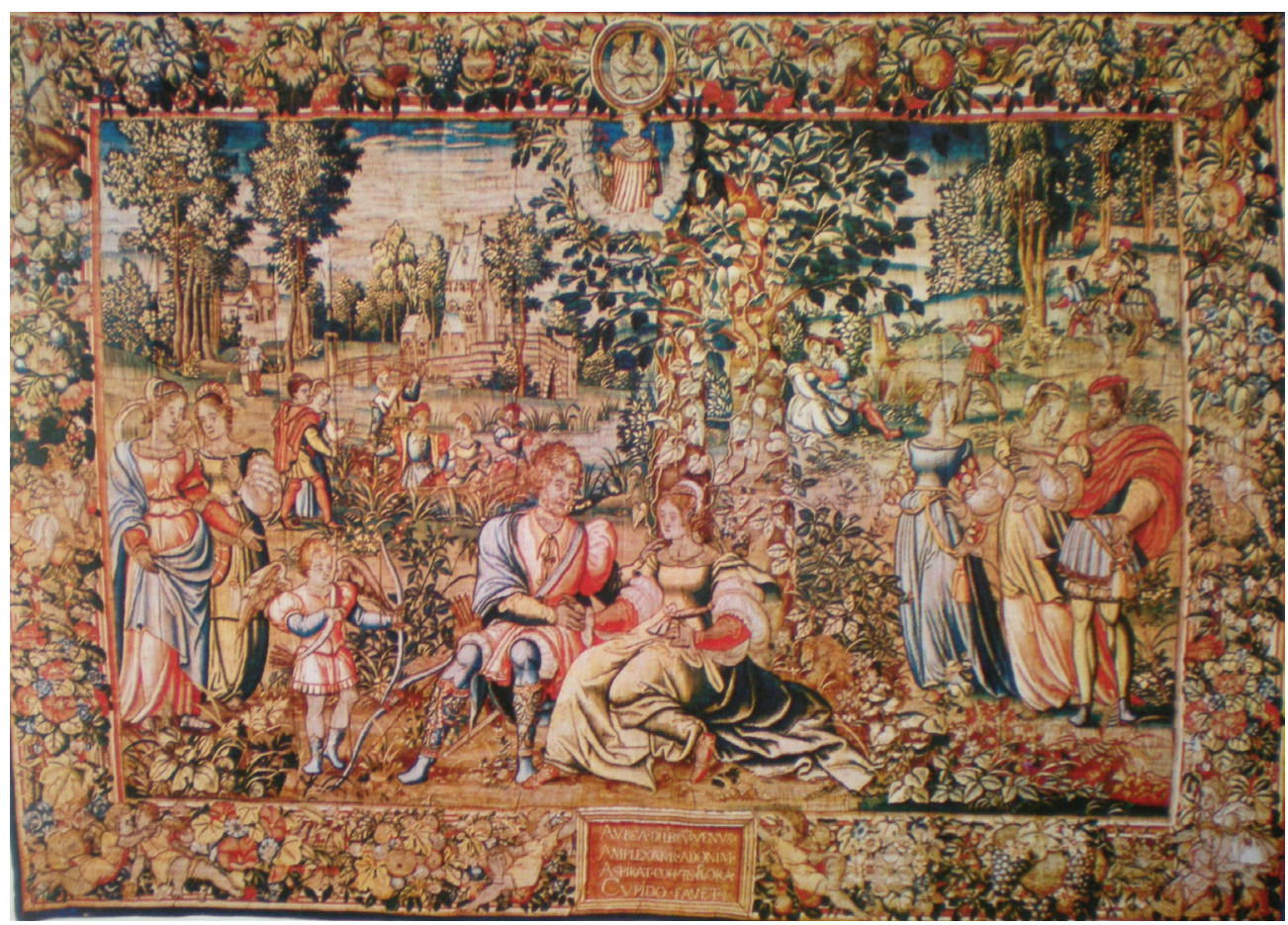

Fig.1. Tapiz del mes de Géminis, Museo de Tapices de la Seo. Zaragoza. Foto: Archivo de la autora.

meses, sobre la que se cierne un nimbo con personajes femeninos y masculinos aún sin identificar. Las orlas que envuelven el campo central de cada uno de los tapices están pobladas de frutos, putti y guirnaldas de flores, acompañados de sendos medallones con la representación de figuras alegóricas de los signos zodiacales.

Respecto a los modelos utilizados en las orlas sacados de grabados, se ha localizado un modelo de la pareja de un sátiro y una ninfa relacionado con el grabado de Alberto Durero, Hércules en la encrucijada ${ }^{8}$ fechado tras su vuelta de Italia en tres de los tapices, concretamente en los de Cáncer, Sagitario y Capricornio. Por nuestra parte, hemos hallado otro modelo entresacado del repertorio de grabados italianos representado en la esquina inferior de las orlas de los paños de Cáncer, Leo y Libra,

escenas: el joven Hércules opta por la Virtud en Tauro, los amores de Venus y el joven Adonis en Géminis, en Leo vemos a Quirón dando lecciones de medicina, y en Libra Hércules en el jardín de las Hespérides. Respecto a los temas históricos: Aries muestra la respuesta del joven Alejandro a los persas, Curio Dentato rechaza los dones de los Samnitas en Cáncer, en Escorpio se narra la historia de César y el tesoro del Tíber, mientras que en Piscis el niño Pretextato miente a su padre; TORRA DE ARANA, Eduardo, HOMBRÍA TORTAJADA, Antero, y DOMINGO PÉREZ, Tomás (1985), op. cit., pp. 263-291

8 MONTOLÍO PALACÍN, Juan Antonio, "Alberto Durero y los tapices de la serie del Zodíaco de La Seo del Salvador de Zaragoza”, en Suplemento El Pilar, nº 5.207 (Julio-Agosto de 2009), pp. 14-15. 
fiel copia del grabado realizado por Marcantonio Raimondi titulado "Sátiro descubre a una ninfa dormida", de la serie Antiguos bajorrelieves ${ }^{9}$.

La autoría de la serie de los Meses de la Seo de Zaragoza aún está por aclarar, tanto en cuanto al cartonista como al propio taller de manufactura licera. La fecha de su realización se encuentra entre los años cincuenta y sesenta del siglo XVI, y debido al italianismo de las figuras y a la realización de los paisajes de gran minuciosidad heredada de la escuela flamenca, se podrían vincular con el artista Michel Cocxie (14991592 $)^{10}$, ligado al mecenazgo de la casa real de los Habsburgo ${ }^{11}$, aunque la factura de esta serie que perteneció a Andrés Santos denota peor calidad en sus composiciones, figuras menos enlongadas y una carencia en la identificación entre el sujeto y la profundidad del campo visual frente a la obra de Cocxie. Según las marcas de taller ubicadas en las orlas de los paños, con variaciones en la doble "b" y el escudo ${ }^{12}$, fueron confeccionados en varios telares de la villa de Bruselas. A tres de los paños, concretamente a los dedicados a Leo, Aquario y Piscis, se añadió otra marca que puede ser de taller o de un licero concreto compuesta por dos triángulos equiláteros enfrentados.

Respecto a otras series de la misma temática en España realizadas durante la segunda mitad del siglo XVI, encontramos noticias sobre la existencia en Zaragoza de catorce paños de Los Planetas citados en el inventario de los bienes de Luis Zaporta en el año 1581, una serie que o bien no ha llegado hasta nosotros, o hasta el momento no se ha podido localizar, y la perdida serie homónima comprada por Felipe II en $1556^{13}$. Respecto al panorama internacional, diversos museos y colecciones custodian tapices con la misma iconografía, como la serie conservada en el Metropolitan Museum of Art de Nueva York, formada por cuatro piezas diseñadas por Bernard van Orley en los años veinte del siglo XVI y titulada las Doce Edades del Hombre ${ }^{14}$, o la

9 OBERHUBER, Konrad (ed.), The illustrated Bartsch. The works of Marcantonio Raimondi and of his school, vol. 26, ñ 223-I (182), New York, Abaris Books, 1978; AZNAR RECUENCO, Mar (2011), op.cit., nota $\mathrm{n}^{\circ} 1$.

10 RÁBANOS FACI, Carmen (1978), op. cit., p. 64.

11 FERNÁNDEZ SORIANO, Víctor, "Michel Cocxie. Pintor grato a la Casa de Habsburgo", en Archivo Español de Arte, t. LXXI, no 322 (abril-junio 2008), pp. 165- 196; CHECA CREMADES, Fernando, Tesoros de la Corona de España. Tapices flamencos en el Siglo de Oro, Bruselas, Sociedad Estatal para la Acción Cultural Exterior, 2010.

12 En 1528 se estableció una ordenanza por la que todos los tapices de Bruselas debían contener la marca de la villa, compuesta por dos B (Bruselas- Brabante) y el escudo, vid: DELMARCEL, Guy, La tapisserie flamade du XVe au XVIIIe siècle, París, Imprimerie Nationale, 1999, pp. 362-365.

13 CHECA CREMADES, Fernando, "Felipe II, el arte de la tapicería y la decoración del Real Alcázar de Madrid", en CHECA CREMADES, Fernando y GARCÍA GARCÍA, Bernardo J., Los triunfos de Aracne. Los tapices flamencos de los Austria en el Renacimiento, Madrid, Fundación Carlos Amberes, 2011, p. 383.

14 STANDEN, Edith Appleton,"The twelve ages of man", en Metropolitan Museum Art Bulletin, vol. 12, $\mathrm{n}^{\circ} 8$ (April, 1954), pp. 241-248. La serie encargada por Andrés Santos dedicada a los Meses aparece citada tempranamente por Standen por su relación temática con los tapices de las "Edades del hombre" del Metropolitan Museum of Art, vid: STANDEN, Edith Appleton, "The twelve ages of man. A Further Study of a Set of Early Sixteenth-Century Flemish Tapestries", en Metropolitan Museum Journal, vol. 2 (1969), pp. 127-168, p. 162; BREMER DAVID, Charissa, "Building American Collections of European tapestries: the role \& influence of French \& Company", en AA. VV., Studies in the Decorative Arts, vol. XI, n 1, New York, Fall-Winter, Bard Graduate Center for Studies in the Decorative Arts, 2003-2004, p. 11. La serie de las "Edades del Hombre fue donada al Metropolitan Museum of Art de Nueva York en 1953, vid: GOLDSMITH 
serie homónima del Victorian \& Albert Museum (Londres) ${ }^{15}$. También encontramos otras series incompletas dedicadas a esta temática en el Musée de Arts Décoratifs de París, la Galerie Moderne de Bruselas ${ }^{16}$, o la serie The Medallion Months, realizada por un artista del círculo de Bernard van Orley posterior a 1528, y que se conserva en diferentes colecciones ${ }^{17}$. La fragmentación de algunas de las series nos hace reflexionar sobre el valor de los tapices de los Meses del cabildo metropolitano de Zaragoza como un importante conjunto de paños que ha llegado completo hasta nosotros.

\section{TAPICES COMPRADOS POR EL CABILDO EN LA ALMONEDA DE LOS BIENES DEL ARZOBISPO}

Además de la serie donada a la sede metropolitana anteriormente comentada, Andrés Santos poseía dos tapices heráldicos con las armas del Duque de Calabria adquiridos por el prelado en Valencia y otra serie de tapices dedicada a la Historia de Moisés. Estas piezas fueron inventariadas junto al resto de bienes del arzobispo tras su muerte, tal y como el propio prelado solicitó en su testamento ${ }^{18}$. Las piezas de tapicería fueron adquiridas por el cabildo zaragozano en la almoneda de los bienes del arzobispo en 1586, una fecha inédita hasta el momento que se documenta en dos recibos de sacristía de la catedral metropolitana de Zaragoza ${ }^{19}$. El segundo de ellos, fechado en julio de dicho año, presenta las cantidades pagadas por cada una de las piezas ${ }^{20}$, que en total sumaban mil ochocientos setenta y seis escudos y catorce sueldos jaqueses del reino de Aragón.

PHILLIPS, John,“ The Renaissance Galleries”, en Metropolitan Museum Journal, vol. 12, n 6 (February, 1954), pp. 145-168.

15 Estas piezas que pudieron hacerse para el Palazzo Vecchio en Florencia, concretamente para el comedor de invierno del duque Cosme de Médicis, entre 1540 y 1550.

16 STANDEN, Edith Appleton (1969), op. cit., p. 162. Estos tapices fueron adquiridos por dicha galería en el año 1563, tras su paso por la Colección Clarke de Nueva York.

17 Los meses de julio y febrero se encuentran en el Art Institute of Chicago y el mes de octubre en el Metropolitan Museum of Art de Nueva York.

18 AHPNZ, Notario Bernabé Lancemán de Sola, 1584, s.f. Encontramos un recibo de sacristía en el que se certifica la realización del inventario de los bienes del arzobispo, vid: ACSZ, Recibos de Sacristía, 19-011586.

${ }^{19}$ El primero de ellos documenta un pago de doce reales a Miguel de Litago por "dos corredores que midieron los paños de raz que se compraran del Señor arçobispo" el 31 de marzo de 1586. ACSZ, Recibos de Sacristía,31-03-1586. Posteriormente, en 1594 se vuelve a documentar la adquisición; ACSZ, Inventario de Sacristía, 1594, f. 69.

20 El encargado de adelantar el dinero para las tapicerías fue Alonso Gregorio, Vicario General durante la prelatura de Andrés Santos y futuro arzobispo de Zaragoza (1593-1602), y se pagaron "122 escudos 8 sueldos los dos reposteros heráldicos, 1107 escudos los ocho paños de la historia de "Moysen", 412 escudos otros cinco piezas (los paños llamados "de Aviego"). Otros 23 escudos 2 sueldos valieron "10 baras y media de damasco carmesí", 80 escudos 4 sueldos 8 dineros costaron 38 varas y 2/3 damasco verde, 3 escudos un "nacre(sic.)", 128 escudos por seis "alhombras" y un escudo por dos pinzadores. Todo ello sumaba en sueldos jaqueses 37.534 mas 8 dineros; ACSZ, Recibos de Sacristía, 13-07-1586. 
TAPICES DE ARMAS CON El ESCUdo heráldico Del DuQue de CALABria

En relación a los dos tapices heráldicos con el escudo del Duque de Calabria, don Fernando de Aragón (1488-1550) ${ }^{21}$, nuestras últimas investigaciones plantean que Andrés Santos pudo adquirir estos dos tapices durante su estancia como inquisidor en Valencia, ciudad a la que llegó el año $1568^{22}$. Sabemos que gran parte de las posesiones de don Fernando de Aragón y su familia pasaron a formar parte de los bienes del Real Monasterio de San Miguel de los Reyes, y que fueron vendidos paulatinamente por los monjes ${ }^{23}$. Las Actas Capitulares del Monasterio de San Miguel de los Reyes, señalan una importante venta de tapicerías que tuvo lugar en $1569^{24}$. Respecto a los paños que poseyó el Duque de Calabria, en el inventario inserto en la Historia de la fundación del monasterio Bernardo de San Bernardo en Valencia e institución en su lugar del de San Miguel de los Reyes, con el testamento del duque de Calabria e inventario de libros y alhajas que dejó él y su esposa Germana de Foix, aparecen dos tapices que contienen "las armas de su excellencia"25.

De los dos tapices heráldicos hemos podido estudiar uno de ellos. El paño se articula mediante una orla que rodea el campo central donde se dispone el escudo heráldico cuartelado del Duque de Calabria rodeado por el Toisón de Oro, en los cuatro ángulos de la pieza aparece la palabra Noscendum, y la orla está poblada por seres fantásticos, pavos reales, jarrones y flores. En el interior del campo del tapiz se despliegan sendas figuras animalísticas rodeadas de motivos vegetales, flores y hojas de acanto carnoso que nos recuerdan a los diseños de otro paño de "verduras" realizado en Grammont durante la segunda mitad del siglo XVI, y que se conserva en el Kunsthistorisches Museum de Viena ${ }^{26}$.

21 FALOMIR FAUS, Miguel, "El Duque de Calabria, Mencía de Mendoza y los inicios del coleccionismo pictórico en la Valencia del Renacimiento", en Ars Longa. Cuadernos de Arte, no 5 (1994), pp. 121-124: ARCINIEGA GARCÍA, Luis, "El legado de la Casa Real de Aragón en Nápoles. Conservación y dispersión", en SAZATORNIL RUIZ, Luis (ed.), Actas del XI Congreso Nacional de Historia del Arte (Valencia, 1998), Valencia, Conselleria de Cultura, Educación y Deporte, 1998, pp. 114-121.

22 Aparece citado en entre los miembros de la inquisición valenciana, en: GARCÍA CÁRCEL, Ricardo, Herejía y sociedad en el siglo XVI. La Inquisición en Valencia. 1530-1609, col. Historia, Ciencia y Sociedad, $\mathrm{n}^{\circ}$ 159, Valencia, ed. Península, 1980, p. 62.Este dato nos llevó a una búsqueda documental en el Archivo Histórico Nacional (citaré: AHN) para corroborar dicha noticia, AHN, Inquisición, Legajo 1184, papel suelto, 1568 .

23 ARCINIEGA GARCÍA, Luis (1998), op. cit., p. 115.

24 AHN, Códices, L. 505, Libro de Actas Capitulares del monasterio jerónimo de San Miguel de los Reyes, Vol. 1, Año 1569 , f. 76 r.

25 AHN, Códices, L. 493.El libro se fecha en los años cincuenta del siglo XVI, aunque la datación no es exacta. El Duque realizó un inventario del que se conserva una copia del siglo XVIII en el Archivo del Reino de Valencia, vid: Archivo del Reino de Valencia, Copia de 1739 del inventario de 1739 de todos los bienes del Duque de Calabria, autorizado por Sebastián Camacho notario el 29 de octubre de 1550, Varios, Caja 83. Otro inventario de sus bienes, en este caso datado en 1527 a su llegada desde Ferrara se custodia en la Biblioteca General e Histórica de la Universitaria de Valencia, vid: Inventari dei Duca de Calabria. Ferrara 1527 , ms. 947.

26 D'HULST, Roger et alii, Tapisseries Flamades du XIVe au XVIIIe siècle, Arcade, deuxieme edition, Bruxelles, 1966 (1960), pp. 257-262. 


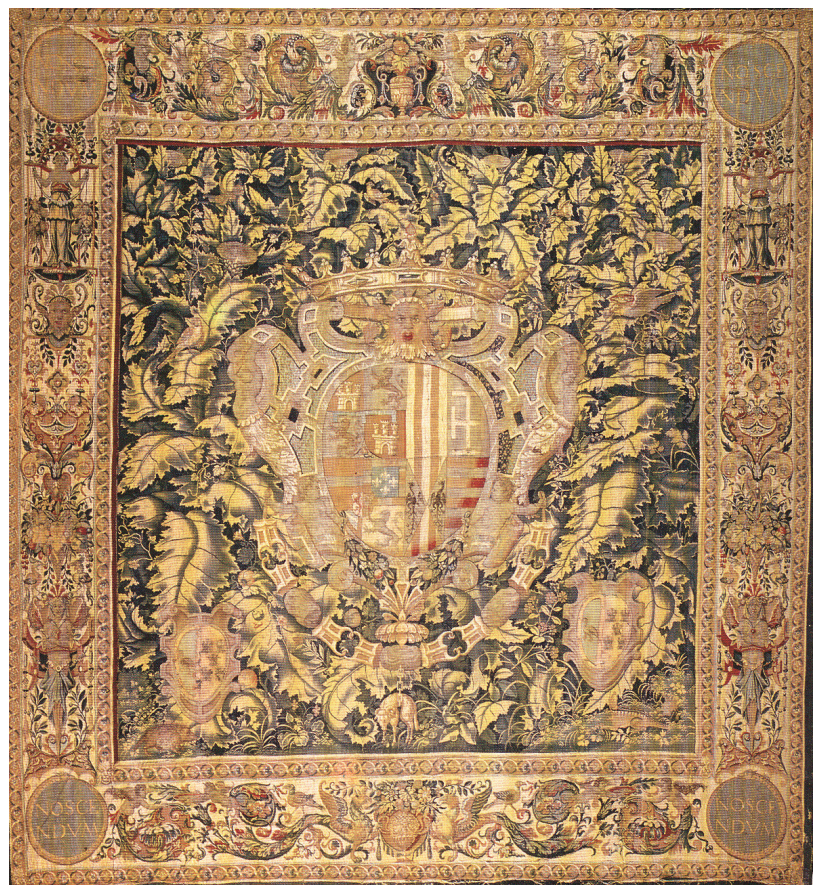

Fig. 2. Repostero heráldico con el escudo del Duque de Calabria, Museo de Tapices de la Seo. Zaragoza. Foto: Archivo de la autora.

Estos paños se fechan en torno a 1540 y se atribuyen al taller de Cornelis de Floris $^{27}$, aunque su diseño también guarda similitudes con la obra de Cornelius Bos ${ }^{28}$. Las marcas del tapiz muestra la doble "b" con el escudete en el centro, obligada a todos los tapices a partir de 1528, y otra marca de la que se ha perdido gran parte.

\section{Serie de la Historia de Moisés}

Los ocho tapices de la Historia de Moisés ${ }^{29}$, también pertenecientes a talleres de mediados del siglo XVI, presentan paisajes, elementos arquitectónicos de corte rena-

\footnotetext{
27 TORRA DE ARANA, Eduardo, HOMBRÍA TORTAJADA, Antero, y DOMINGO PÉREZ, Tomás (1985), op. cit., pp. 318-320.

28 SCHELE, Sune, Cornelis Bos: A Study of the Origins of the Netherland Grotesque, catalogue raisonnée du Nationalmuseum, Stockholm, Almquvist/Wiksell, 1965.

29 Concretamente, los ocho de la primera serie citada, han llegado hasta nosotros con los nombres de: Moisés sacado del Nilo ( Ex.2, 1-7), Moisés entregado a su propia madre (Ex.2, 7-10), Moisés niño devuelto a la princesa ( Ex.2, 10-11), Moisés niño quita la corona al Faraón, Moisés niño pisa la corona del Faraón, Moisés defiende a la hijas de Jetró ( Ex.2, 16-18), Moisés presentado a Jetró por una de sus hijas (Ex.2, 21-22), y Moisés en el monte Horeb ( Ex.3, 1-22), vid: TORRA DE ARANA, Eduardo, HOMBRÍA TORTAJADA, Antero, y DOMINGO PÉREZ, Tomás (1985), op. cit., p. 240-266.
} 


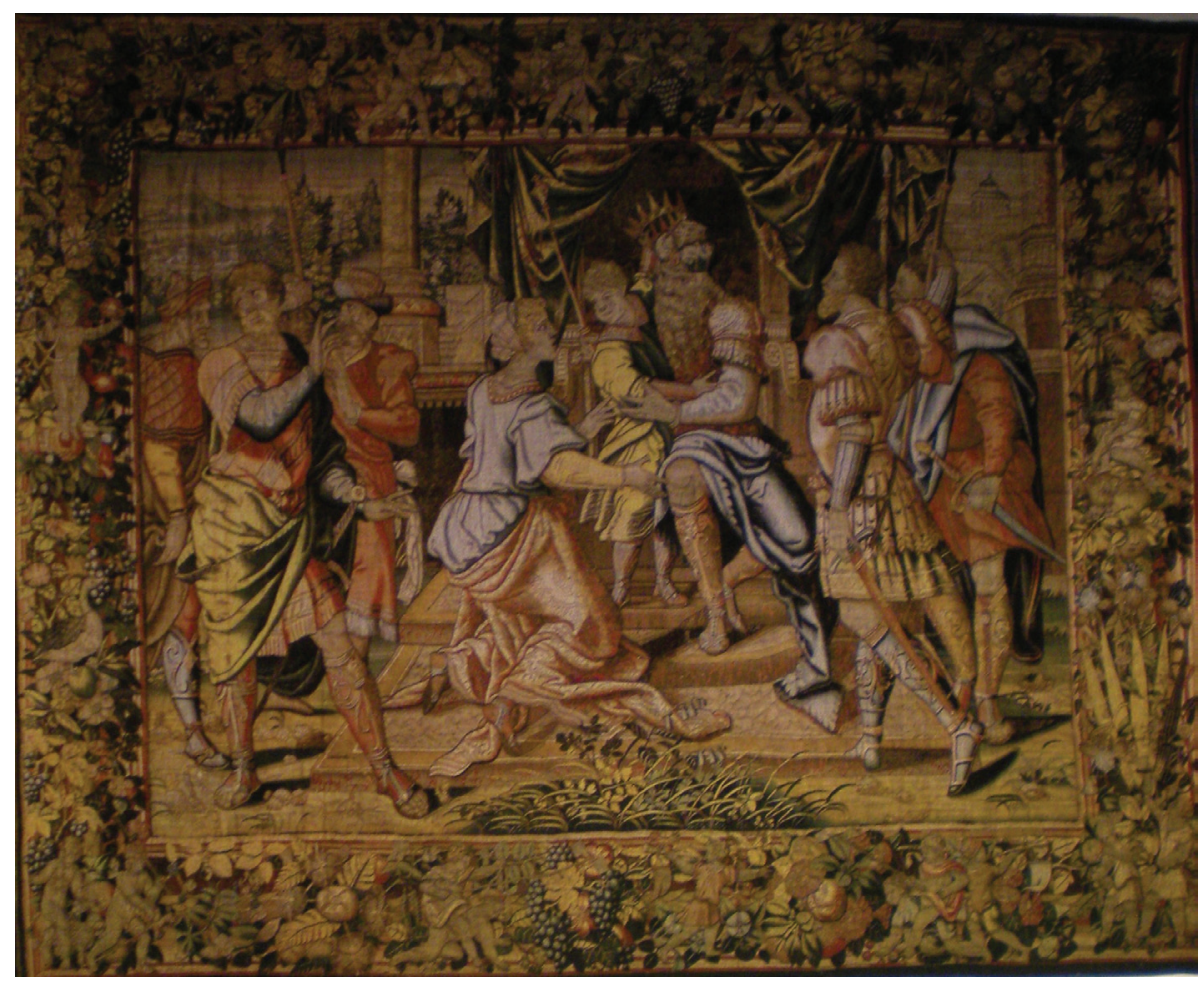

Fig. 3. Moisés niño quita la corona al Faraón, Museo de Tapices de la Seo. Zaragoza. Foto: Archivo de la autora.

ciente y figuras herederas de los modelos rafaelescos, características de estos talleres de la segunda mitad del siglo XVI. En las orlas con motivos que penetran en el campo central, vemos la utilización de guirnaldas flamencas junto al empleo de grutescos.

La iconografía de la Historia de Moisés está vinculada tanto al propio Exodo como a la tradición apócrifa medieval derivada de escritos teológicos como el Speculum Humanae Salvationis ${ }^{30}$, en el que la figura de Moisés se equipara a la de Cristo, y a las leyendas apócrifas derivadas de las Biblias versificadas de Herman de Valenciennes y de Geoffroy de París. Un claro ejemplo es la escena del tapiz "Moisés pisa la corona del faraón", alusión a la derrota del paganismo y por tanto, al episodio en que los ídolos caen al paso del Hijo de Dios (Mt. 2, 15).

El diseño de la serie se acerca en la concepción compositiva a las obras de Frans Geubels y Cornelius Tons, a pesar de que los modelos no son homogéneos. Los

30 HAUF I VALLS, Albert, "De L'Speculum Humanae Salvationis a L 'Spill de Jaume Roig: Itinerari especular i figural”, en Estudis Romànics, n² 23, 2001, pp. 173-219. Un ejemplar el Speculum Humanae Salvationis se puede consultar on line: Det Kongelige Bibliotek (Copenhague), ms. GKS. 80, $2^{\circ}$ : http://www.kb.dk/ da/index.html (página consultada el 10 de febrero de 2011). 
paños de "Moisés en el Monte Horeb" y "Moisés presentado a Jetró por una de sus hijas", pertenecen a otro cartonista frente al que realizó el resto del conjunto, y según las marcas de los propios tapices, fueron realizados por dos talleres de la villa de Bruselas bien diferenciados ${ }^{31}$.

La representación iconográfica de esta serie en la tapicería fue común durante el siglo XVI y XVII, y encontramos exponentes de la misma temática en la propia Península Ibérica. El primero se encuentra de nuevo en la capital del Ebro, concretamente en la Colección de la Universidad de Zaragoza, comprada a la familia de las Balsas en 1828 y perteneciente a talleres de Bruselas del siglo XVII ${ }^{32}$. También se conservan dos tapices de la misma historia en el Museo de Toledo, que se corresponden con un depósito de la catedral primada de la ciudad homónima, ${ }^{33} \mathrm{y}$ dos tapicerías dedicadas a Moisés conservadas en la Colección Real que pertenecieron a María de Hungría ${ }^{34}$.

Todo ello nos hace valorar la importancia de los tapices propiedad de Andrés Santos como muestra del prestigio de su propietario, que venido de una familia humilde y careciendo de un escudo de armas propio, decidió adquirir los dos tapices heráldicos del Duque de Calabria. En cuanto a las dos series de tapices, es posible que las pudiera adquirir en alguna almoneda en Valencia, Valladolid o Zaragoza, una búsqueda que está en proceso y de la que esperamos extraer más datos de interés.

31 BERTRAND, Pascal-François, "Les tapissiers flamands en France aux XVe el XVIe siécles", en DELMARCEL, Guy (ed.), Flemish tapestry weaver abroad. Emigration and the founding of manufactories in Europe, Lovaina, Leuven University Press, 2002, pp. 218-220.

32 RÁBANOS FACI, Carmen, "Estudio documental de la colección de tapices de la Universidad de Zaragoza", en Artigrama, no 10, 1993, pp. 424-427.

33 CORTÉS HERNÁNDEZ, Susana, Tapices del Museo de Santa Cruz de Toledo, Toledo, Consellería de Cultura, Turismo y Artesanía de Castilla-La Mancha, 2010, p. 10.

34 HERRERO CARRETERO, Concepción, "La Colección de Tapices de la Corona de España. Notas sobre su formación y conservación”, en Arbor, CLXIX, nº65 (Mayo 2001), p. 168. 